\title{
Front Matter: Volume 10141
}

, "Front Matter: Volume 10141," Proc. SPIE 10141, Selected Papers of the Chinese Society for Optical Engineering Conferences held July 2016, 1014101 (7 November 2016); doi: 10.1117/12.2262027

SDIE Event: Selected Proceedings of the Chinese Society for Optical Engineering SPIE. Conferences held July 2016, 2016, Changchun, China 


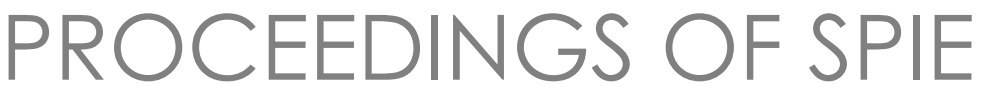

\title{
Selected Papers of the Chinese Society for Optical Engineering Conferences held July 2016
}

\author{
Yueguang LV \\ Weimin Bao \\ Guangjun Zhang \\ Editors
}

12-14 and 22-26 July 2016

Beijing and Changchun, China

\section{Organized by}

Chinese Society for Optical Engineering (China)

Photoelectronic Technology Committee, Chinese Society of Astronautics (China)

Science and Technology on Electro-Optical Information Security Control Laboratory (China)

Sponsored by

Chinese Academy of Engineering (China)

National Natural Science Foundation of China (China)

Chinese Society for Optical Engineering (China)

China High-Tech Industrialization Association(China)

Published by

SPIE 
The papers in this volume were part of the technical conference cited on the cover and title page. Papers were selected and subject to review by the editors and conference program committee. Some conference presentations may not be available for publication. Additional papers and presentation recordings may be available online in the SPIE Digital Library at SPIEDigitallibrary.org.

The papers reflect the work and thoughts of the authors and are published herein as submitted. The publisher is not responsible for the validity of the information or for any outcomes resulting from reliance thereon.

Please use the following format to cite material from these proceedings:

Author(s), "Title of Paper," in Selected Paperss of the Chinese Society for Optical Engineering Conferences held July 2016, edited by Yueguang Lv, Weimin Bao, Guangjun Zhang, Proceedings of SPIE Vol. 10141 (SPIE, Bellingham, WA, 2016) Seven-digit Article CID Number.

ISSN: 0277-786X

ISSN: 1996-756X (electronic)

ISBN: 9781510607279

ISBN: 9781510607286 (electronic)

Published by

SPIE

P.O. Box 10, Bellingham, Washington 98227-0010 USA

Telephone +1 3606763290 (Pacific Time) · Fax +1 3606471445

SPIE.org

Copyright @ 2016, Society of Photo-Optical Instrumentation Engineers.

Copying of material in this book for internal or personal use, or for the internal or personal use of specific clients, beyond the fair use provisions granted by the U.S. Copyright Law is authorized by SPIE subject to payment of copying fees. The Transactional Reporting Service base fee for this volume is $\$ 18.00$ per article (or portion thereof), which should be paid directly to the Copyright Clearance Center (CCC), 222 Rosewood Drive, Danvers, MA 01923. Payment may also be made electronically through CCC Online at copyright.com. Other copying for republication, resale, advertising or promotion, or any form of systematic or multiple reproduction of any material in this book is prohibited except with permission in writing from the publisher. The CCC fee code is 0277-786X/16/\$18.00.

Printed in the United States of America.

Publication of record for individual papers is online in the SPIE Digital Library.

\section{SPIE. DIGRARY}

Paper Numbering: Proceedings of SPIE follow an e-First publication model. A unique citation identifier (CID) number is assigned to each article at the time of publication. Utilization of CIDs allows articles to be fully citable as soon as they are published online, and connects the same identifier to all online and print versions of the publication. SPIE uses a seven-digit CID article numbering system structured as follows:

- The first five digits correspond to the SPIE volume number.

- The last two digits indicate publication order within the volume using a Base 36 numbering system employing both numerals and letters. These two-number sets start with 00, 01, 02, 03, 04, $05,06,07,08,09,0 A, 0 B \ldots$. OZ, followed by 10-1Z, 20-2Z, etc. The CID Number appears on each page of the manuscript. 


\title{
Contents
}

\author{
vii Authors \\ xi Conference Committee \\ xiii Introduction
}

SELECTED PROCEEDINGS OF THE CHINESE SOCIETY FOR OPTICAL ENGINEERING CONFERENCES HELD JULY 2016

1014102 Measure short separation for space debris based on radar angle error measurement information [10141-9]

1014103 An efficient two-dimensional ALE modelling and experimental validation for pulsed laser-matter interaction [10141-10]

1014104 Gaussian total variation blind restoration of ground-based space object imagery [10141-18]

1014105 Research on the development of space target detecting system and three-dimensional reconstruction technology [10141-20]

1014106 Application of femtosecond laser range finder in space debris monitoring [10141-21]

1014107 Modeling and correction of static pointing error of level mounting telescope [10141-28]

1014108 Research of radiation resistant Er doped fiber for space detection [10141-41]

1014109 A high-precision K-band LFMCW radar for range measurement [10141-45]

10141 OA Research on calibration error of carrier phase against antenna arraying [10141-51]

$10141 \mathrm{OB}$ The online estimation of relative alignments for multiple heads star tracker based on the invariability of inter-star angle principle [10141-56]

$101410 \mathrm{C}$ Weak point target detection in star sensor [10141-69]

10141 OD Enhanced multi-view prediction structure [10141-70]

$10141 \mathrm{OE}$ A conjunction of photons statistic and wave inferometry in interstellar space communication [10141-71]

10141 OF Research on the optical system for space optical clock at NTSC [10141-73]

10141 OG Design and analysis of control system for VCSEL of atomic interference magnetometer [10141-74] 
$101410 \mathrm{H}$

10141 이

101410

10141 OK

$101410 \mathrm{~L}$

$101410 M$

10141 ON

1014100

10141 OP

$101410 Q$

10141 OR

10141 OS

$101410 T$

$101410 U$

$101410 V$

10141 OW

$101410 X$

10141 OY

$101410 Z$

1014110

1014111

1014112

Fabrication of the new structure 980nm VCSEL [10141-75]

Study on the etching process GaAs-based VCSEL [10141-76]

Time-varying property of electron density in plasma sheath and its effect on EM wave at Ka band [10141-39]

Software development for electromagnetic scattering of aircraft in near space [10141-44]

Research on informational operation application of tactical loitering platform [10141-55]

Proportional navigation law design of plane-symmetrical vehicle with terminal attack angle constraint for over target flight [10141-63]

A double candidate survivable routing protocol for HAP network [10141-72]

Linear response of an instrument entitled Sky Radiometer [10141-16]

Numerical calculation of the plume infrared radiation of a long-endurance UAV [10141-23]

Application of joint orthogonal bases in compressive sensing ghost image [10141-24]

Plasma radome designed for the EMP effects defense [10141-25]

The design of parabolic cylindrical antenna with light emitting plasma [10141-59]

Research on polarization bidirectional reflectance characteristic of metal paint surfaces [10141-1]

Error analysis of angular resolution for direct intercepting measurement laser warning equipment [10141-3]

Photon counting chirped amplitude modulation lidar using an asymmetric triangular wave modulation [10141-4]

Simulation of multiplying electron distribution in electron multiplier layer for EBAPS [10141-5]

The design of cathode for organic photovoltaic devices [10141-6]

Based on B-splines non-rigid registration method for atmospheric turbulence degraded image [10141-8]

Adaptive optics image restoration algorithm based on wavefront reconstruction and adaptive total variation method [10141-12]

Small high-speed dynamic target at close range laser active imaging system [10141-13]

Reflectance and reflection phase of photonic crystal with anisotropic left-handed materials [10141-14]

Highly sensitive detection using Herriott cell for laser absorption spectroscopy [10141-15] 
1014113 Design and FPGA implementation of real-time automatic image enhancement algorithm [10141-17]

1014114 Thermostatic system of sensor in NIR spectrometer based on PID control [10141-19]

1014115 Based on coherent detection of Rayleigh - Brillouin temperature measurement [10141-22]

1014116 The review on infrared image restoration techniques [10141-26]

1014117 Research on pseudo-color image generation technology of the distribution of gaseous pollutants [10141-27]

1014118 Simulating the spatial resolution of the framing camera [10141-32]

1014119 A high accuracy image registration method research of polarization [10141-34]

10141 1 A Two-dimensional photon counting imaging detector based on PCB delay line anode [10141-35]

10141 1B The relationship between the size of $x$-ray focal spot and image geometry definition [10141-36]

$101411 \mathrm{C}$ The method of $\mathrm{x}$-ray image intensifies pixel matching and noise suppression based on the CCD [10141-37]

10141 1D Transmission characteristics of $\mathbf{x}$-ray in MCP collimator in parallel structure [10141-38]

$10141 \mathrm{lE}$ Research on polarization imaging information parsing method [10141-40]

$10141 \mathrm{IF}$ Fabrication of the curved artificial compound eyes with a homebuilt mold [10141-42]

10141 1G Demonstration of single pixel computational ghost imaging with pseudo-randomly patterned illumination from a liquid crystal display [10141-46]

$10141 \mathrm{lH}$ Multi-spectral image enhancement algorithm based on keeping original gray level [10141-47]

101411 Measuring the thermal expansion coefficient of the carbon fiber optical tube by heterodyne laser interferometry [10141-48]

$101411 \mathrm{~J}$ An algorithm of super-resolution based on phase shifting [10141-49]

10141 1K Faint spatial object classifier construction based on data mining technology [10141-50]

10141 1L Study on characteristics of chirp about Doppler wind lidar system [10141-52]

$101411 \mathrm{M}$ Enhancement of low quality reconstructed digital hologram images based on frequency extrapolation of large objects under the diffraction limit [10141-53]

10141 1N Design of a solar-blind ultraviolet detection system [10141-54]

1014110 A novel rain removal technology based on video image [10141-57] 
$10141 \mathrm{lP}$ Simulative calculation of the Earth surface temperature variation in certain place of Xinjiang, China during summer daytime [10141-58]

$101411 Q$ Design of a solar-blind ultraviolet zoom lens in corona detection [10141-60]

10141 IR Development and application of a thermoelectric cooler extended area blackbody [10141-61]

10141 is Enhancement system of nighttime infrared video image and visible video image [10141-64]

10141 1T Infrared image gray adaptive adjusting enhancement algorithm based on gray redundancy histogram-dealing technique [10141-65]

$101411 \mathrm{U}$ A method of image compression based on lifting wavelet transform and modified SPIHT [10141-66]

10141 1V Research on flight stability performance of rotor aircraft based on visual servo control method [10141-67]

10141 1W Measurement of modulation transfer function for space remote sensing TDDICCD camera [10141-68]

$101411 \mathrm{X}$ Astrometric calibration for space debris with a small field of view [10141-7]

$101411 \mathrm{Y}$ The preparation of the nonlinear optical quantum dots in organic polymer composite [10141-11] 


\section{Authors}

Numbers in the index correspond to the last two digits of the six-digit citation identifier (CID) article numbering system used in Proceedings of SPIE. The first four digits reflect the volume number. Base 36 numbering is employed for the last two digits and indicates the order of articles within the volume. Numbers start with 00, 01, 02, 03, 04, 05, 06, 07, 08, 09, OA, OB...0Z, followed by 10-1Z, 20-2Z, etc.

Bai, Xiaohong, 18, 1A

Bai, Yonglin, 18, 1A

Cao, Weiwei, 18, 1A

Cen, Longzhu, OV

Chang, $\mathrm{H} ., \mathrm{OF}$

Che, Jinxi, oU

Chen, Guifen, 0 Z

Chen, Jing, IV

Chen, Li, IG

Chen, Lin-xiang, $1 \mathrm{~L}$

Chen, Ruo-Wang, 1P, IT

Chen, Weijun, 1D

Chen, Xiaohong, 1M

Chen, Xiuwei, 09

Chen, $X U, 1 X$

Chen, $Y i, O Q$

Chen, YU, IN, IQ

Cheng, Bin, OU

Cheng, Hui-yan, OB

Cheng, Jing, $1 G$

Cheng, Li, OR

Cheng, YuBao, 17

Cheng, Zheng-dong, $0 Q$

Dai, Qin, 10

Dong, GuoWei, 13

Dong, Zhiwei, 03

Du, Jianxiang, $1 \mathrm{~J}$

Du, Junju, $1 \mathrm{X}$

Du, Li-fang, $1 \mathrm{~L}$

Du, Yang, 12

Duanmu, Qingduo, OW, OX

Fan, Ren-jie, 00

Fan, Wenwen, $1 \mathrm{~N}, 1 \mathrm{Q}$

Fan, Xiang, $0 Q, 16$

Fan, Xiaoyan, 05

Feng, Xiaoyu, $1 \mathrm{~J}$

Feng, Yuan, $\mathrm{OH}, \mathrm{Ol}$

Feng, Yun-song, OP

Gao, Dongyang, $1 \mathrm{X}$

Gou, Yongsheng, 18, 1 A

Guo, Difu, $1 X$

Guo, H. C., OE

Guo, Shiping, 04

Guo, Yongcai, IF

Guo, Zhenxi, OM

Han, J. X., OF

Han, YiPing, OK

$\mathrm{HaO}$, Yongqin, $\mathrm{OH}, \mathrm{Ol}$

Hao, Zi-long, $1 T$
He, Panfeng, ON

He, Wenjun, 11

Hou, Xiaomin, OA

Hou, ZuoXun, 13

Hu, Mai, 12

Hu, Shaoming, $1 x$

Hu, Yihua, 15

Huang, Baokun, 15

Huang, Guochang, $1 Y$

Huang, Jian-ping, 08

Huang, Zhang-bin, OP

Ji, Denggao, OM

$\mathrm{Ji}$, Rongyi, 06

Ji, Xufei, 14

Jia, Yingzhuo, 09

Jiang, Cong, 08

Kang, Sirui, 1N, 1Q

Kang, Yongqiang, 11

Kou, Jun, OG

Lei, Fanpu, $1 \mathrm{~A}$

Lei, Hao, IR

Li, Chunyan, OC, OD

Li, Chunyue, ON

Li, Dong, 05

$\mathrm{Li}$, Dongming, OY, OZ

Li, Guoshu, OL

$\mathrm{Li}$, Jie, OG

$\mathrm{Li}$, Jisheng, 04

Li, Meng-meng, 07

Li, Run-dong, 08

Li, Sijian, 16

Li, Xiaojun, OE

Li, Xiao-long, 02

$\mathrm{Li}$, Xiaoping, OJ

Li, Xiao-xia, OP

$\mathrm{Li}, \mathrm{Xin}, 13$

Li, Xuejian, 1B

$\mathrm{Li}$, Yang, $\mathrm{OH}, \mathrm{Ol}$

Li, Ye, OW, OX, 1B, 1C, 1D

$\mathrm{Li}, \mathrm{Yi}, \mathrm{OC}, \mathrm{OD}$

$\mathrm{Li}$, Zaijin, $\mathrm{OH}, \mathrm{Ol}$

$\mathrm{Li}$, Zhang, $\mathrm{OE}$

Li, Zhen-wei, 07

Li, Zhi-gang, OR, OS

Liang, Zheng-yu, OQ

Liao, Yurong, $1 \mathrm{~K}$

Liao, Zhibo, $1 \mathrm{~J}$

Liv, Baiyu, 18

Liu, Changhai, 04 
Liu, Cheng-zhi, 07

Liu, Chunyang, OW

Liu, Da, OB, OC, OD

Liu, Guojun, OH, OI

Liu, Huan, OY, OZ

Liu, Jinguo, 1U, IW

Liu, Ning, $1 \mathrm{M}$

Liu, Shuo, 10

Liu, Wei, 00

Liv, Xiao, OT

Liu, Yang, OS

Liu, Yanyang, 1B

Liu, Yong, IT

Lou, Xin, 1K

Luo, Jiasai, $1 \mathrm{~F}$

LV, Panfeng, OY

LV, Shiliang, IU, IW

Ma, Kun, OV

$\mathrm{Ni}$, Shuyan, ON

Nie, Yong-ming, $1 \mathrm{~K}$

Pan, Maosen, $1 Y$

Pan, Zheng, 13

Piao, Xue, OW

Piao, Yan, 10, 15

Qiao, Liwei, 14

Qin, Junjun, 18, 1A

Qin, Xulei, 1B, 1C, 1D

Ren, Zhang, OG

Shao, Li, 17

Shen, Haibin, OM

Sheng, Huai Jie, 17

Shi, Feng, OW, OX

Shi, Jia-ming, OS

Shi, Lei, OJ

Song, Dawei, 05

Song, De, OW, OX

Song, Guangming, 12

Song, Jin, OW

Song, Jinxing, OL

Song, Lijun, $1 G$

Sun, Ke, OA

Sun, Wenfeng, 05

Sun, Xian-zhong, $1 \mathrm{R}$

Sun, Xiao-jie, OG

Tang, Qi, 13

Tian, X., OF

Tian, Yuqi, 11

Wang, Bao-Guo, IP

Wang, Bo, 18, 1A

Wang, Dong, 00

Wang, Du-yue, 10

Wang, Feng, OT, 19

Wang, Feng, OV

Wang, Hongjun, OU

Wang, Huanhuan, OL

Wang, Jiachun, OR

Wang, Ji-hong, $1 \mathrm{~L}$

Wang, Li, OC, OD

Wang, Pu-pu, 08

Wang, Qiao, 02
Wang, Qichao, OR

Wang, Tian, $1 \mathrm{H}$

Wang, Ting, $\mathrm{OZ}$

Wang, Wenju, 12

Wang, Xiaoguang, $1 G$

Wang, Xiaolong, OT, 19, 1E

Wang, Xiaogian, 1U, IW

Wang, Xin, $1 \mathrm{~F}$

Wang, Yue, is

Wang, Zhihong, 14

Wei, Zhen, 05

Wei, Zong-kang, OG

Wu, Bin, OM

Wu, Yan-peng, OB

Wu, Yunzhi, OT

Xia, Xuan, OX

Xiao, Chun, 08

Xiong, Ya-zhou, OB, OC, OD

$\mathrm{Xu}$, Bo-Hong, IP

$\mathrm{XU}$, Linli, $1 \mathrm{H}$

Xu, Peng, 18

$X u$, Rong, 04

$\mathrm{Xu}$, WangLong, OK

$\mathrm{Xu}$, Wen-qing, $0 \mathrm{O}$

Yan, Changling, $\mathrm{OH}, \mathrm{OI}$

Yang, Chao, $1 \mathrm{M}$

Yang, Feng, OG

Yang, Guo-tao, $1 \mathrm{~L}$

Yang, Jiao, 17

Yang, Jinhua, $0 Z$

Yang, Weiping, $1 \mathrm{H}$

Yao, Baoli, 11

Yao, Bo, oJ

Yao, Jun, 10

Yin, Fang, OC, OD

Yu, Dabin, $1 Y$

Yu, Shengtao, 1C

YU, Yanan, IV

Yuan, Hongwu, 19, $1 \mathrm{E}$

Yuan, Jiang, 06

Yue, Chuan, $1 \mathrm{~L}$

Zeng, Jie, OS

Zeng, Xianfang, 19

Zhang, Chunmin, 11

Zhang, Ge, 08

Zhang, Jiabin, $\mathrm{OH}, \mathrm{OI}$

Zhang, Jiandong, OV

Zhang, Jianfei, OM

Zhang, Ji-kui, OS

Zhang, Jin, IR

Zhang, Jinchun, OU

Zhang, Jinhua, $1 Y$

Zhang, Jun, OL

Zhang, Kai, 1 I

Zhang, Lei, 11

Zhang, Lijuan, $\mathrm{OY}, \mathrm{OZ}$

Zhang, Rongzhi, 04

Zhang, S., OF

Zhang, Wen-Ming, IP

Zhang, Xiao-nan, OG 
Zhang, Y. M., OE

Zhang, Yao, 02

Zhang, Ya-zhou, IR

Zhang, Yue, 10

Zhang, Yunhao, OL

Zhang, Zheng, 10

Zhang, Zhuo, 02

Zhang, Zijing, OV

Zhao, Chongyi, 12

Zhao, Dapeng, IY

Zhao, Minghui, $1 Y$

Zhao, Qiang, 03

Zhao, Wei, 00

Zhao, Xiaojun, 12

Zhao, Xuan, 11

Zhao, Yang, IK

Zhao, Yuan, OV

Zheng, Dong, 16

Zheng, Junhao, OY

Zheng, Yeliang, 15

Zhong, Liujun, 12

Zhou, Cheng, $1 \mathrm{G}$

Zhou, Lai-jian, 02

Zhou, Pucheng, $1 \mathrm{E}$

Zhou, Weihu, 06

Zhou, Zhe, 00

Zhu, Bin Cheng, 16

Zhu, Bin, OQ

Zhu, Bingli, 18, 1A

Zong, Xiaoying, $1 \mathrm{~J}$

Zou, H. X., OF

Zou, Yongliao, 09

Proc. of SPIE Vol. 10141 1014101-9

Downloaded From: https://www.spiedigitallibrary.org/conference-proceedings-of-spie on 26 Apr 2023 Terms of Use: https://www.spiedigitallibrary.org/terms-of-use 


\title{
Conference Committee
}

\author{
Conference Chairs
}

Weimin Bao, China Aerospace Science and Technology Corporation

(China)

Jianquan Yao, Tianjin University (China)

Lijun Wang, Changchun Institute of Optics, Fine Mechanics and

Physics (China)

Huilin Jiang, Changchun University of Science and Technology

(China)

Ming Li, China Academy of Space Technology (China)

Yueguang Lv, China Northern Institute of Electronic Equipment (China)

Zuyan Xu, Technical Institute of Physics and Chemistry (China)

Yue Hao, Xidian University (China)

Yongjian Liu, Science and Technology on Complex Aviation Systems Simulation Laboratory (China)

Guangjun Zhang, Southeast University (China)

Title Committee

Zejin Liu, National University of Defense Technology (China)

Zizheng Gong, China Academy of Space Technology (China)

Wei Zhang, Science and Technology on Electro-Optical Information Security Control Laboratory (China)

Jin Guo, State Key Laboratory of Laser Interaction with Matter (China)

Xiangang Luo, Institute of Optics and Electronics (China)

Yadong Jiang, University of Electronic Science and Technology of China (China)

Program Committee

Jing Liu, National Astronomical Observatories (China)

Xiaoquan Sun, State Key Laboratory of Pulsed Power Laser Technology (China)

Wei Zhao, Key Laboratory of Electro-Optical Countermeasures, Test, and Evaluation Technology (China)

Shensheng Han, Shanghai Institute of Optics and Fine Mechanics (China)

Weiqi Jin, Beijing Institute of Technology (China)

Xiangjun Wang, Tianjin University (China) 


\section{Introduction}

We had the great honor of organizing The Third International Symposium on Monitoring, Early Warning, Removal Technology of Space Targets and Debris, The Fourth International Conference on Frontiers in Optical Imaging Technology and Applications, and The Second International Symposium on Photoelectric Defense Technologies. It was truly a great pleasure for us to greet more than 800 participants from many different countries attending these three symposia. We firmly believe these symposia will become important international events in the field of optical technology.

The Third International Symposium on Monitoring, Early Warning, Removal Technology of Space Targets and Debris, The Fourth International Conference on Frontiers in Optical Imaging Technology and Applications, and The Second International Symposium on Photoelectric Defense Technologies are sponsored by the Chinese Academy of Engineering, National Natural Science Foundation of China, Chinese Society for Optical Engineering, and China High-tech Industrialization Association. These symposia are organized by Chinese Society for Optical Engineering and Photoelectronic Technology Committee, Chinese Society of Astronautics and Science and Technology on Electro-Optical Information Security Control Laboratory.

The purpose of these three symposia is to provide a forum for the participants to report and review innovative ideas and up-to-date progress and developments and discuss the novel approaches to application in the optical field. It is sincerely hoped that the research and development in the optical field and international cooperation will be promoted and thus sharing of the common interest will be enhanced.

On behalf of other chairs, co-chairs, and the organization committee of these three conferences, I would like to heartily thank our sponsors and organizers for all they have done for the symposia. Thanks also to all the authors for their contributions to the proceedings, to all of the participants and friends for their interest and efforts in helping us to make the symposia possible, to the program committee for their effective work and valuable advice, and especially the secretariat and the SPIE staff or their tireless effort and outstanding services in preparing the symposia and publishing the proceedings.

\section{Yueguang LV Weimin Bao Guangjun Zhang}

